Article

\title{
Exploring the Effects of Contextual Factors on Residential Land Prices Using an Extended Geographically and Temporally Weighted Regression Model
}

\author{
Zhengyuan Chai ${ }^{1}$, Yi Yang ${ }^{1, *}$, Yangyang Zhao ${ }^{2}$, Yonghu $\mathrm{Fu}^{1}$ and Ling Hao ${ }^{3}$ \\ 1 School of Marine Technology and Geomatics, Jiangsu Ocean University, Lianyungang 222005, China; \\ chaizhengyuan@jou.edu.cn (Z.C.); huhu_0902@jou.edu.cn (Y.F.) \\ 2 Research Center of Government GIS, Chinese Academy of Surveying and Mapping, Beijing 100830, China; \\ zhaoyy@casm.ac.cn \\ 3 Meteorological Observation Centre, Lianyungang Meteorological Bureau, Lianyungang 222000, China; \\ 880033@nuist.edu.cn \\ * Correspondence: yangyi@jou.edu.cn
}

check for updates

Citation: Chai, Z.; Yang, Y.; Zhao, Y.; $\mathrm{Fu}, \mathrm{Y}$;; Hao, L. Exploring the Effects of Contextual Factors on Residential Land Prices Using an Extended Geographically and Temporally Weighted Regression Model. Land 2021, 10, 1148. https://doi.org/ 10.3390/land 10111148

Academic Editors: Guanghui Jiang, Yanbo Qu, Hongyun Si and Yan Song

Received: 13 September 2021

Accepted: 26 October 2021

Published: 28 October 2021

Publisher's Note: MDPI stays neutral with regard to jurisdictional claims in published maps and institutional affiliations.

Copyright: (c) 2021 by the authors. Licensee MDPI, Basel, Switzerland. This article is an open access article distributed under the terms and conditions of the Creative Commons Attribution (CC BY) license (https:// creativecommons.org/licenses/by/ $4.0 /)$.

\begin{abstract}
A spatial and temporal heterogeneity analysis of residential land prices, in general, is crucial for maintaining high-quality economic development. Previous studies have attempted to explain the geographical evolution rule by studying spatial-temporal heterogeneity, but they have neglected the contextual information, such as school district, industrial zone, population density, and job density, associated with residential land prices. Therefore, in this study, we consider contextual factors and propose a revised local regression algorithm called the contextualized geographically and temporally weighted regression (CGTWR), to effectively address spatiotemporal heterogeneity, and to creatively extend the feasibility of importing the contextualization into the GTWR model. The quantitative impact of contextual information on residential land prices was identified in Shijiazhuang (SJZ) city from 1974 to 2021. Empirical analyses demonstrated that school district and industrial zone factors played important roles in residential land prices. Notably, the distance from a residential area to an industrial zone was significantly positively correlated with residential land prices. In addition, a positive relationship between school districts and residential land prices was also observed. Finally, the $\mathrm{R}^{2}$ value of the CGTWR model was $92 \%$, which was superior to those of ordinary least squares (OLS, 76\%), geographically weighted regression (GWR, 85\%), contextualized geographically weighted regression (CGWR, 86\%), and GTWR (90\%) models. These evaluation results indicate that the CGTWR algorithm, which incorporates contextual information and spatiotemporal variation, could provide policy makers with evidence for understanding the nature of varying relationships within a land price dataset in China.
\end{abstract}

Keywords: residential land prices; spatial and temporal non-stationarity; contextualized geographically and temporally weighted regression; Shijiazhuang

\section{Introduction}

A spatial and temporal heterogeneity analysis of residential land prices is considered to be crucial for revealing major issues in real estate market development, understanding effective strategies of economic macro control, and promoting high-quality development of internal economics [1-4]. In the past decades, urbanization in China has undergone rapid development. The urban population increased from $17.16 \%$ to $60.60 \%$ between 1974 and 2019 according to the China Statistical Yearbook. Along with the expeditious progression of urbanization, countless internal markets have flourished. The housing market is one of the most active markets in China and plays a crucial role in China's economy [5-9]. The average selling price of commercial housing has increased rapidly, especially in heavily populated provinces. By contrast, the per capita disposable income of urban households has increased 
from 5425 to 42,358 yuan (equivalent to approximately 838.16-6544 USD). The swift growth of residential land prices as compared with the increase in residents' incomes indicates a growing housing affordability problem in China [10-13]. Thus, the spatiotemporal analysis of residential land prices has become a research priority for researchers and policy makers.

Considering the related available research, various models have been developed to explore the spatial and temporal heterogeneity in residential land prices. Geographic information system (GIS)-based approaches, called automated valuation methods (AVMs), are characterized by a powerful theoretical and methodological basis in order to determinate more objective property evaluations [14-17]. Multiple criteria are aggregated into a compound criterion by the multi-attribute utility theory (MAUT) for the purpose of evaluating the decisive property characteristics in the real estate market $[18,19]$. Hybrid data-driven regression models that incorporate a multi-objective genetic algorithm have been proposed to search expressions about maximization of data accuracy and simplification of mathematical functions [20-22]. Furthermore, the geographically weighted regression (GWR) model, which provides distance metrics with specific parameters in the spatial dimensions, was introduced by [23-25]. The mixed geographically weighted regression (MGWR) model has been verified effectively with some parameters fixed globally and others adjusted locally [26,27]. A prominent advancement in residential land price estimations resulted from the geographically and temporally weighted regression (GTWR) approach, proposed by Bo Huang [28]. The GTWR model provides an efficient approach for evaluating mass price temporal non-stationarity in the field of real estate market.

These techniques have made outstanding contributions towards determining the factors such as floor area, building age, and distance to the nearest central business district (CBD) that affect a rapid rise in real estate prices [29-32]. In addition to building structural and locational requirements, contextual attributes, obviously, also affect changes in residential land prices. For instance, two schools are near each other, but one has better educational facilities and resources; the selling prices of houses near these schools would be influenced by the neighborhood-level attribute space [33-36]. Rich Harris [30] proposed a contextualized geographically weighted regression (CGWR) to integrate attribute correlations between neighborhood-level observations and found that it was significant in a real estate context, but temporal information was ignored. Few studies have made efforts to simultaneously consider contextual and spatiotemporal non-stationarity, although there is an obvious need to do so. Our study aimed to fill this gap and to provide a valuable recommendation for the healthy development of a real estate market.

In this study, a new contextualized GTWR algorithm, named the CGTWR, is proposed by reconstructing spatiotemporal weights. In contrast to previous approaches that only consider spatial and temporal non-stationarity or neighborhood information, this approach extends the GTWR and CGWR algorithms, focusing on redesigning the weight function using neighborhood information in attribute space. Moreover, better fitting ability can be gained through optimizing contextual and spatiotemporal factors. Applications of the CGTWR technique could be used for evaluating residential land value to determine a more adequate and objective property value. The CGTWR model could implement an effective way for large-scale estimation of residential land price and supply evidence for policy makers to understand the nature of varying relationships within a house price dataset in China.

The remainder of this paper is organized as follows: In Section 2, we briefly describe the study area, data source, and methods, using the CGTWR approach; in Section 3, we present the case study results with residential land price data using the CGTWR model, and compare the performance of the CGTWR model with global and local models; finally, we present the discussion and conclusions in Sections 4 and 5, respectively. 


\section{Materials and Methods}

\subsection{Study Area}

The study area included the Chang'an, Qiaoxi, Xinhua, and Yuhua Administrative Districts, located in SJZ city, Hebei Province, covering approximately $408.76 \mathrm{~km}^{2}$ (from $37^{\circ} 58^{\prime} 2.58^{\prime \prime}$ to $38^{\circ} 10^{\prime} 1.25^{\prime \prime} \mathrm{N}$ and from $114^{\circ} 22^{\prime} 4.99^{\prime \prime}$ to $114^{\circ} 42^{\prime} 6.40^{\prime \prime} \mathrm{E}$ ) and encompassing a population of 2.74 million people (Figure 1). As a central city in the southern part of the Beijing-Tianjin-Hebei Economic Rim, ongoing rapid economic and urbanization development have been taking place in SJZ city. The GDP (gross domestic product) of this city accounted for $16.54 \%$ of the province as reported by the Hebei Economic Yearbook in 2019. At the same time, the urbanization rate of the permanent population was $65.05 \%$, making it one of the high-growth zones in China according to the Shijiazhuang Statistical Yearbook. Moreover, the area of urban construction land increased from 425 square kilometers in 2013 to 2194 square kilometers in 2019, and the average selling price of commercialized buildings increased from 4931 yuan $(\approx 763.32$ USD) to 10,452 yuan ( $\approx 1617.97$ USD) per square meter at this stage. Against the background of rapid economic and urbanization development, the question of whether the real estate market in SJZ city can develop orderly and favorably has become a matter of deep anxiety and concern. Meanwhile, this region, over recent decades, has become one of the most seriously environmentally contaminated cities in China. This area had the highest annual average particulate matter (PM2.5) value among major cities of China in 2020 [37-41]. Improving the utilization rate of land and promoting sustainable economic advancement in SJZ city is a critical issue for achieving high-quality development in this region. Therefore, considering the contradictions between human and environmental relationships, we investigated SJZ city to explore the spatiotemporal heterogeneity in the real estate economy with urban development and calculated the characteristic indexes to describe the residential land price factors.

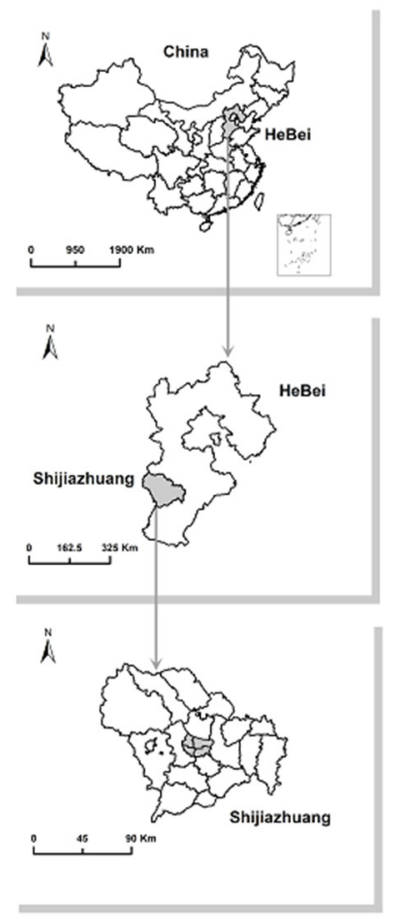

(a)

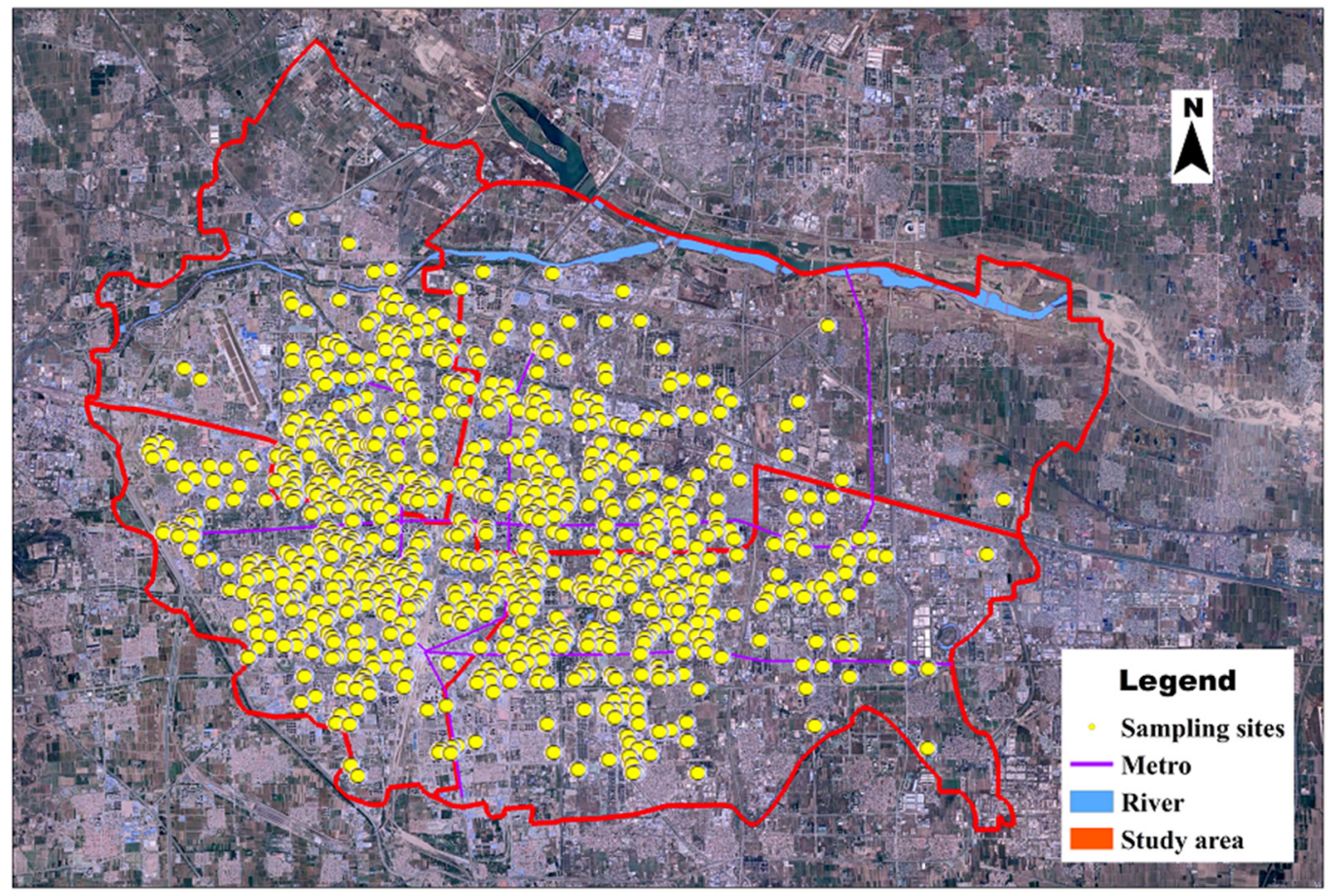

(b)

Figure 1. Map of the study area in SJZ city: (a) Geographical locations at national, provincial, and city scales; (b) Google Earth images, in 2021, at local scales. 


\subsection{Data Source}

According to the hedonic theory [42] and data availability, the dataset consisted of 913 housing data collected from the Anjuke.com website (https://sjz.anjuke.com/, accessed on 25 January 2021). We selected residential land price data with precise geographical locations, including plot ratio (PlOT), number of bathrooms (BATH), floor area (AREA), and age of building (YEAR), as the research objects. The natural logarithm of explanatory variables was used $[28,43,44]$. The houses in school districts and the population density information were up-to-date and authoritative, and obtained from the Shijiazhuang Education Bureau and China State Statistical Bureau, respectively. The detailed statistical information of the variables in SJZ city is shown in Table 1.

Table 1. The definitions of the dependent and independent variables.

\begin{tabular}{|c|c|c|c|c|c|c|}
\hline Variables & Abbreviation & Min & Max & Mean & Std. & VIF \\
\hline \multicolumn{7}{|l|}{ Dependent variables } \\
\hline Residential land prices (CNY) & PRICE & 250,000 & $7,150,000$ & $1,456,421$ & 718,386 & - \\
\hline \multicolumn{7}{|l|}{ Structural explanatory variables } \\
\hline Plot ratio (\%) & PlOT & 0.400 & 5.840 & 2.299 & 0.880 & 1.121 \\
\hline Total number of bathrooms & BATH & 0.000 & 3.000 & 1.200 & 0.437 & 2.243 \\
\hline Total floor area $\left(\mathrm{m}^{2} ;\right.$ except basement $)$ & AREA & 29.000 & 282.000 & 93.223 & 32.569 & 3.341 \\
\hline Age of building at time of sale (year, 1974-2021) & YEAR & 1.000 & 48.000 & 34.434 & 9.730 & 1.813 \\
\hline \multicolumn{7}{|l|}{ Locational explanatory variables } \\
\hline $\begin{array}{l}\text { Take the logarithm of distance to the nearest transport } \\
\text { facility including bus, subway and train station }(\mathrm{km})\end{array}$ & Log $D_{\text {subway }}$ & 2.732 & 6.946 & 5.113 & 0.603 & 1.065 \\
\hline $\begin{array}{l}\text { Take the logarithm of distance to the nearest central } \\
\text { business district }(\mathrm{km})\end{array}$ & $\log D_{c b d}$ & 0.657 & 8.047 & 5.429 & 0.885 & 1.223 \\
\hline $\begin{array}{l}\text { Take the logarithm of distance to the nearest central } \\
\text { shopping plaza }(\mathrm{km})\end{array}$ & Log $\mathrm{D}_{\text {shopping }}$ & 3.206 & 8.631 & 6.423 & 0.737 & 1.152 \\
\hline Take the logarithm of distance to the nearest park $(\mathrm{km})$ & Log $D_{\text {park }}$ & 3.046 & 8.470 & 6.630 & 0.644 & 1.105 \\
\hline Take the logarithm of distance to the nearest river $(\mathrm{km})$ & $\log \mathrm{D}_{\text {river }}$ & 3.854 & 9.000 & 7.540 & 0.603 & 1.101 \\
\hline \multicolumn{7}{|l|}{ Neighborhood explanatory variables } \\
\hline School district housing (Yes: 1, No: 0 ) & SCHOOL & 0 & 1 & 0.049 & 0.216 & 1.050 \\
\hline Take the logarithm of distance to the nearest factory $(\mathrm{km})$ & $\log D_{\text {factory }}$ & 3.696 & 7.858 & 6.365 & 0.639 & 1.072 \\
\hline Take the logarithm of population density (people $/ \mathrm{km}^{2}$ ) & $\log D_{\text {pop }}$ & 2.284 & 815.783 & 115.119 & 106.048 & 1.194 \\
\hline Take the logarithm of job density (job $/ \mathrm{km}^{2}$ ) & $\log \mathrm{D}_{\text {job }}$ & 0.73 & 7346.440 & 135.541 & 452.350 & 1.012 \\
\hline
\end{tabular}

Notes: Min, minimum; Max, maximum; Std., standard error; VIF, variance inflation factor.

We applied the non-Euclidean distance (non-ED) metric to locational explanatory variables in order to overcome the inaccurate coefficient estimation of Euclidean distance (ED) measurement and the misinterpreted spatial pattern estimation due to linear measurement [45-47]. Multicollinearity, which can generate misleading regression coefficients and standard errors, refers to the high correlation or mutual correlation between the independent variables in the regression model $[48,49]$. Thus, to examine the statistical significance and collinearity of variables in the study area (Section 3.2), the variance inflation factor (VIF) was used, the values of which were all less than 4 (much less than 10, which is the typical threshold for concern). The analytical framework of modeling the real estate estimation is shown in Figure 2. 


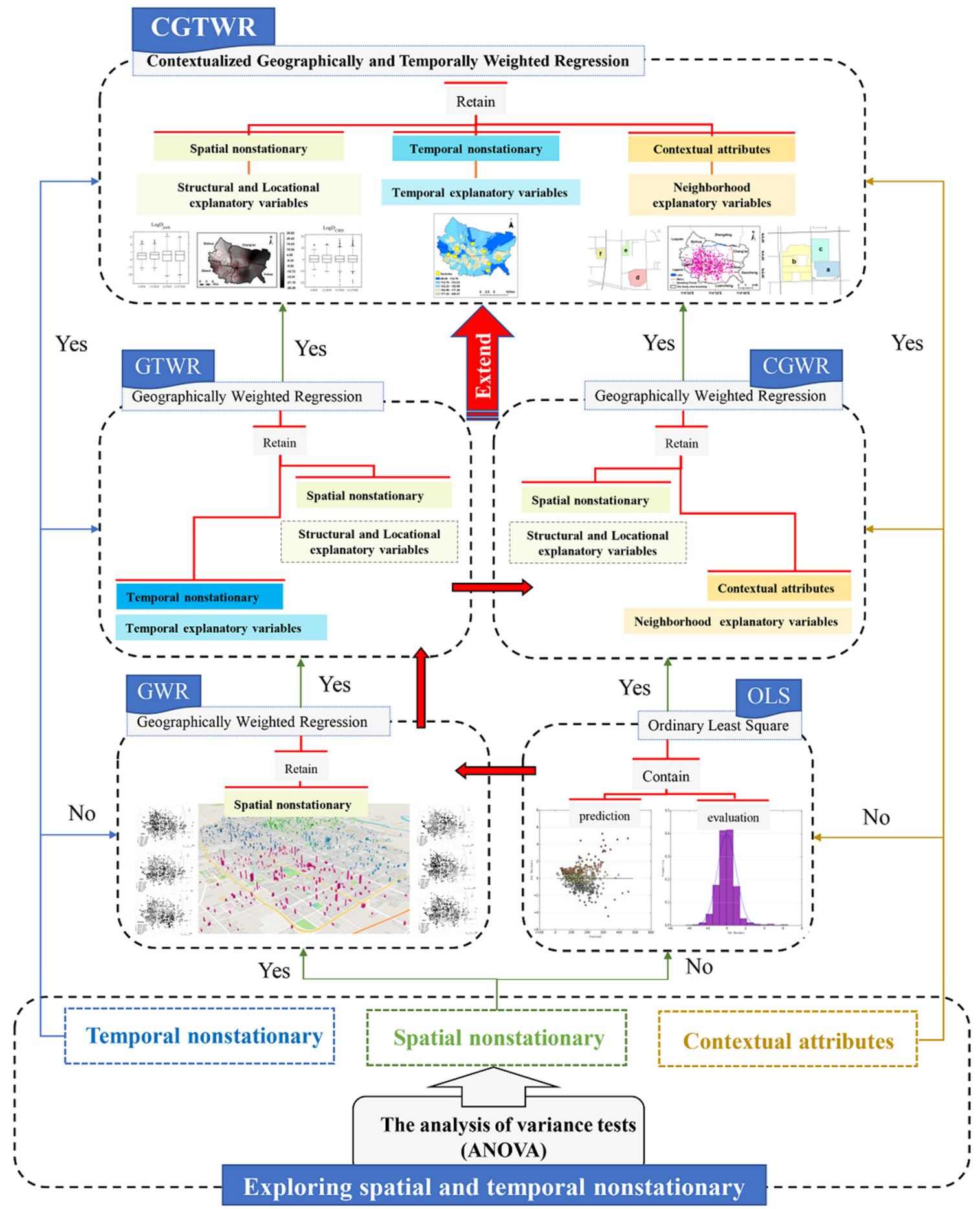

Figure 2. Analytical framework of the modeling methods used.

\subsection{Methods}

2.3.1. Geographically and Temporally Weighted Regression

The GTWR approach is a spatially and temporally varying local regression model that is extensively used in statistical economic research [28]. It is especially useful for correlation analysis in healthcare, environmental protection, and real estate markets $[45,50,51]$. The GTWR model is given as follows:

$$
y_{i}=\beta_{0}\left(u_{i}, v_{i}, t_{i}\right)+\sum_{k=1}^{p} \beta_{k}\left(u_{i}, v_{i}, t_{i}\right) X_{i k}+\varepsilon_{i}, i=1,2, \cdots, n .
$$


The local coefficients are derived by the GTWR to manifest spatiotemporal heterogeneity synchronously by importing temporal effects into the GWR [28]. Here, $\left(u_{i}, v_{i}, t_{i}\right)$ represents the prescribed coordinate of point $i$ in location $\left(u_{i}, v_{i}\right)$ at time $t_{i}, \beta_{0}\left(u_{i}, v_{i}, t_{i}\right)$ represents the intercept value, and $\beta_{k}\left(u_{i}, v_{i}, t_{i}\right)$ expresses a group of values for the figure $p$ of coefficients at sample $i$. The error obeying a standard normal distribution at random is defined by $\varepsilon_{i}, \varepsilon_{i} \sim N\left(0, \sigma^{2}\right)$. Random errors at different points are irrelevant, i.e., $\operatorname{Cov}\left(\varepsilon_{i}, \varepsilon_{j}\right)=0(i \neq j)$.

The $\hat{\beta}_{i}$ (regression coefficient) at sample point $i$ can be computed by the least-squares algorithm as:

$$
\hat{\beta}_{i}\left(u_{i}, v_{i}, t_{i}\right)=\left(X^{\prime} W\left(u_{i}, v_{i}, t_{i}\right) X\right)^{-1} X^{\prime} W\left(u_{i}, v_{i}, t_{i}\right) y_{i} .
$$

The fitted value $\hat{y}$ is:

$$
\hat{y}=\left[\begin{array}{c}
\hat{y}_{1} \\
\hat{y}_{2} \\
\cdots \\
\hat{y}_{n}
\end{array}\right]=\left[\begin{array}{c}
X_{1}\left(X^{\prime} W\left(u_{1}, v_{1}, t_{1}\right) X\right)^{-1} X^{\prime} W\left(u_{1}, v_{1}, t_{1}\right) \\
X_{2}\left(X^{\prime} W\left(u_{2}, v_{2}, t_{2}\right) X\right)^{-1} X^{\prime} W\left(u_{2}, v_{2}, t_{2}\right) \\
\cdots \\
X_{n}\left(X^{\prime} W\left(u_{n}, v_{n}, t_{n}\right) X\right)^{-1} X^{\prime} W\left(u_{n}, v_{n}, t_{n}\right)
\end{array}\right] y .
$$

Here, the weighting matrix $W\left(u_{i}, v_{i}, t_{i}\right)$ is found to calculate the weight function using distances between the regression point $i$ and the sample points as the variable. In GTWR models, two kernel functions are widely used to determine the weights, namely, fixed and adaptive types [28]. A self-adapting kernel function is applied to achieve an optimal spatial kernel bandwidth for the study area. We use the Gaussian function as the weighting function:

$$
W_{i j}=\exp \left(-\frac{d_{i j}^{2}}{h^{2}}\right)
$$

where $h$ is a non-negative constant called a bandwidth, which decreases as the distance increases between locations $i$ and $j$.

\subsubsection{Extension to GTWR with Neighborhood-Level Similarity}

Considering spatial and temporal non-stationarity, spatiotemporal distance, $d^{S T}$, can be described as follows:

$$
d^{S T}=d^{S} \otimes d^{T}
$$

where $\otimes$ represents different operators, and $d^{S}$ and $d^{T}$ stand for the spatial and temporal distance, respectively. Harris [30] proposed a contextualized spatial distance $d^{C S}$ as follows:

$$
d^{C S}=d^{C} \otimes d^{S}
$$

Therefore, the neighborhood information is used in the contextual GTWR approach inspired by Huang [28] and Harris, and a modified contextual and spatiotemporal distance $d^{C S T}$ can be given as:

$$
d^{C S T}=d^{C} \otimes d^{S T}=d^{C} \otimes d^{S} \otimes d^{T}
$$

According to Huang, operator + was adopted, which means that contextual spatiotemporal distance $d^{C S T}$ is the linear combination of contextual distance $d^{C}$, spatial distance $d^{S}$, and temporal distance $d^{T}$ as follows:

$$
\left(d^{C S T}\right)^{2}=\varphi^{C}\left(d^{C}\right)^{2}+\varphi^{S}\left(d^{S}\right)^{2}+\varphi^{T}\left(d^{T}\right)^{2}
$$

The contextual and spatiotemporal distance $d_{i j}^{C S T}$ between regression points $\left(u_{I}, I, I_{i}\right)$ and $\left(u_{j}, v_{j}, t_{j}\right)$ is described as follows:

$$
\left(d_{i j}^{C S T}\right)^{2}=\varphi^{C}\left(d_{i j}^{C}\right)^{2}+\varphi^{S}\left(d_{i j}^{S}\right)^{2}+\varphi^{T}\left(d_{i j}^{T}\right)^{2}
$$


where $\varphi^{C}, \varphi^{S}$, and $\varphi^{T}$ are scale factors used to counterbalance the contextual, spatial, and temporal effects among $d_{i j}^{C}, d_{i j}^{S}$, and $d_{i j}^{T}$.

The contextual distance $d_{i j}^{C}$, spatial distance $d_{i j}^{S}$ and temporal distance $d_{i j}^{T}$ between regression points $\left(u_{i}, v_{i}, t_{i}\right)$ and $\left(u_{j}, v_{j}, t_{j}\right)$ can be found as follows:

$$
\left\{\begin{array}{c}
\left(d_{i j}^{C}\right)^{2}=\left[f\left(z_{i}-z_{j}\right)\right]^{2} \\
\left(d_{i j}^{S}\right)^{2}=\left(u_{i}-u_{j}\right)^{2}+\left(v_{i}-v_{j}\right)^{2} . \\
\left(d_{i j}^{T}\right)^{2}=\left(t_{i}-t_{j}\right)^{2}
\end{array}\right.
$$

where index score function $f\left(z_{i}-z_{j}\right)$ is given to estimate the contextual distance in the neighborhood level. The contextual spatiotemporal distance can be described as:

$$
\begin{aligned}
& \left(d_{i j}^{C S T}\right)^{2}=\varphi^{C}\left(d_{i j}^{C}\right)^{2}+\varphi^{S}\left(d_{i j}^{S}\right)^{2}+\varphi^{T}\left(d_{i j}^{T}\right)^{2} \\
& \quad=\varphi^{C}\left[f\left(z_{i}-z_{j}\right)\right]^{2}+\varphi^{S}\left[\left(u_{i}-u_{j}\right)^{2}+\left(v_{i}-v_{j}\right)^{2}\right]+\varphi^{T}\left(t_{i}-t_{j}\right)^{2}
\end{aligned}
$$

The contextualized and spatiotemporal kernel function $W_{i j}^{C S T}$ can be formulated as:

$$
\begin{aligned}
& W_{i j}^{C S T}=\exp \left\{-\frac{\left(d_{i j}^{C S T}\right)^{2}}{\left(b^{C S T}\right)^{2}}\right\} \\
& =\exp \left\{-\frac{\varphi^{C}\left(d_{i j}^{C}\right)^{2}+\varphi^{S}\left(d_{i j}^{S}\right)^{2}+\varphi^{T}\left(d_{i j}^{T}\right)^{2}}{\left(b^{C S T}\right)^{2}}\right\} \\
& =\exp \left\{-\frac{\varphi^{C}\left(d_{i j}^{C}\right)^{2}}{\left(b^{C S T}\right)^{2}}\right\} \times \exp \left\{-\frac{\varphi^{S}\left(d_{i j}^{S}\right)^{2}+\varphi^{T}\left(d_{i j}^{T}\right)^{2}}{\left(b^{C S T}\right)^{2}}\right\} \\
& =\exp \left\{-\varsigma \times\left[f\left(z_{i}-z_{j}\right)\right]^{2}\right\} \times \exp \left\{-\left(\frac{\left(d_{i j}^{S}\right)^{2}}{b_{S}^{2}}+\frac{\left(d_{i j}^{T}\right)^{2}}{b_{T}^{2}}\right)\right\} \\
& =\exp \left\{-\varsigma \times\left[f\left(z_{i}-z_{j}\right)\right]^{2}\right\} \times \exp \left\{-\frac{\left(d_{i j}^{S}\right)^{2}}{h_{S}^{2}}\right\} \times \exp \left\{-\frac{\left(d_{i j}^{T}\right)^{2}}{h_{T}^{2}}\right\} \\
& =W_{i j}^{C} \times W_{i j}^{S} \times W_{i j}^{T}
\end{aligned}
$$

where $W_{i j}^{C}, W_{i j}^{S}$ and $W_{i j}^{T}$ are contextual, spatial, and temporal kernel functions.

In order to determine the optimal contextualized and spatiotemporal factor $\tau, \varsigma$, the performance of CGTWR should be measured using criterion:

$$
C V(\tau, \varsigma)=\sum_{i}\left[y_{i}-\hat{y}_{\neq i}(\tau, \varsigma)\right]^{2}
$$

The pseudo-code of CGTWR is presented in Algorithm 1. 


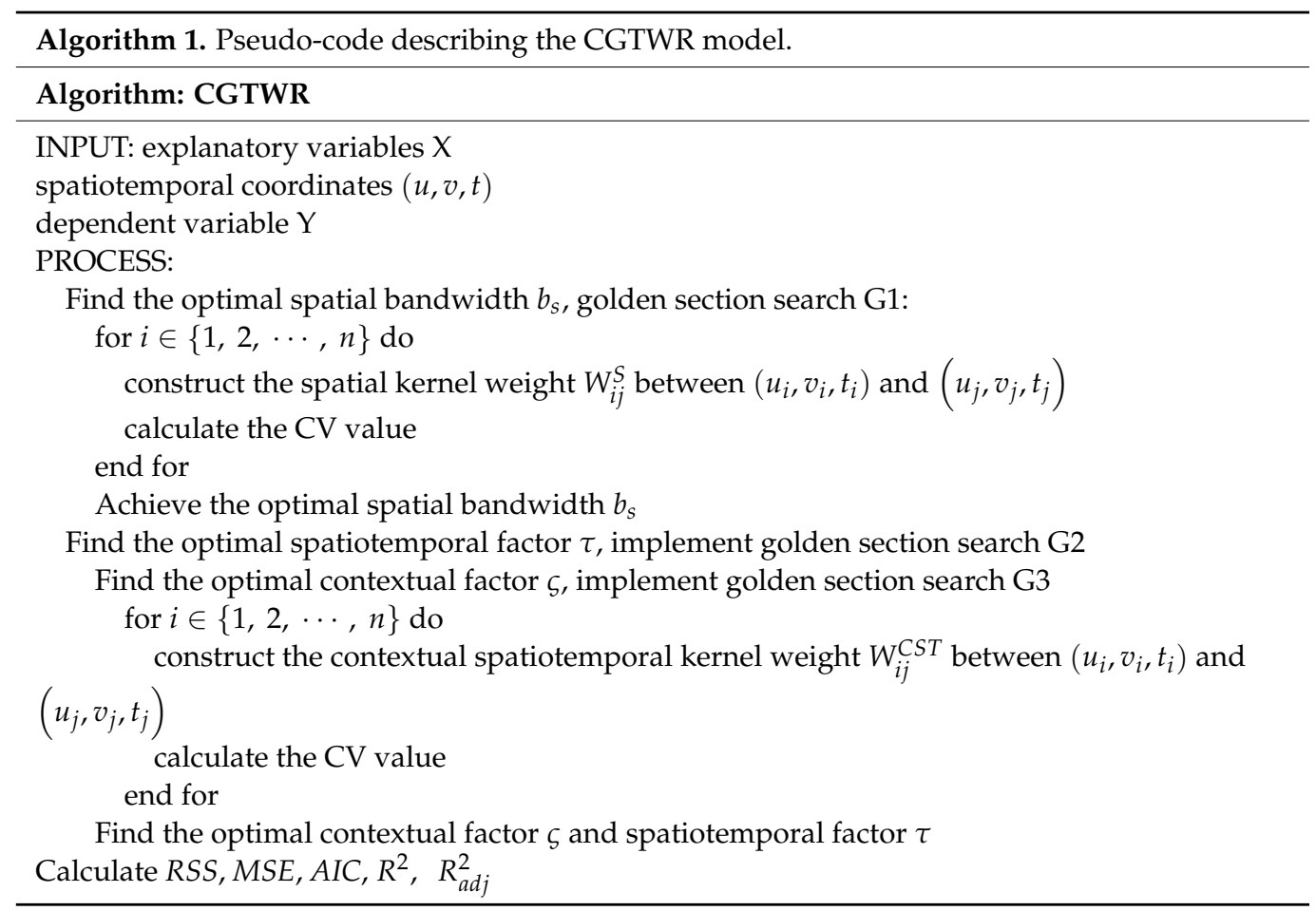

\subsubsection{Model Evaluation of Performance}

Statistical indicators were adopted in this study to evaluate the performance of different models on estimating the coefficients. The residual sum of squares (RSS) between the estimated and actual value at each point in the dataset could be normalized by the total variation as follows:

$$
R S S=\sum_{i=1}^{n} \varepsilon_{i}{ }^{2}=\sum_{i=1}^{n}\left(y_{i}-\hat{y}_{i}\right)^{2}
$$

where $y_{i}$ and $\hat{y}_{i}$ denote the estimated and actual values, respectively, in the experimental dataset, and $n$ is the number of observations. Mean square error (MSE) is a standardized variance estimation based on actual and estimated value. The overall estimated coefficient can be measured as follows:

$$
M S E=\frac{\sum_{i=1}^{n}\left(y i-\hat{y}_{i}\right)^{2}}{n}
$$

where $n, y_{i}$, and $\hat{y}_{i}$ are defined as in (1). In addition, $R^{2}$ can estimate the goodness of fit for different models as follows:

$$
R^{2}=1-\frac{\sum_{i=1}^{n}\left(y i-\hat{y}_{i}\right)^{2}}{\sum_{i=1}^{\mathrm{n}}(y i-\bar{y})^{2}}
$$

when the number of independent variables in the regression model is large, the complex determination coefficient increases gradually, and the degree of interpretation of variables decreases. In order to overcome this shortcoming of the sample determination coefficient, we appropriately adjust $R^{2}$ to improve the goodness of fit of the regression equation. The $R_{a d j}^{2}$ value is given as follows:

$$
R_{a d j}^{2}=1-\left[\frac{n-1}{n-\operatorname{tr}(s)-1}\left(1-R^{2}\right)\right]
$$

where $R^{2}$ can be computed from Equation (4) and $\operatorname{tr}(s)$ is the effective number of parameters. 


\section{Experimental Results and Comparisons}

\subsection{Results of the Global Model}

Before exploring possible spatiotemporal and contextual variations of residential land price determinants in SJZ city, the global model represents the average relationships between the residential land prices and explanatory factors. Global models generate only one parameter estimate for the residential land price data at all locations, assuming the linkages between this covariate and the dependent variable is stationary over space. In order to acquire a comprehensive understanding of the influences of various factors on residential land price, we list the parameter estimates associated with each covariate in the ordinary least square (OLS) model. The parameter estimates generated by OLS are listed in Table 2, with and without the contextual variables. Those statistically significant values at the $5 \%$ level are marked with an asterisk ${ }^{* \prime}$.

Table 2. Parameter estimates for the regression of residential land prices generated by OLS.

\begin{tabular}{|c|c|c|c|c|c|c|}
\hline \multirow[b]{2}{*}{ Parameter } & \multicolumn{3}{|c|}{ Model 1} & \multicolumn{3}{|c|}{ Model 2} \\
\hline & Coefficient & Std. Error & $p$-Value & Coefficient & Std. Error & $p$-Value \\
\hline Intercept & 41.803 & 22.706 & $0.066^{*}$ & 9.275 & 26.108 & $0.723 *$ \\
\hline PlOT & -1.230 & 1.409 & 0.383 * & -0.354 & 1.395 & 0.800 * \\
\hline BATH & 13.709 & 4.051 & 0.001 & 14.477 & 3.983 & 0.000 \\
\hline AREA & 1.565 & 0.066 & 0.000 & 1.561 & 0.066 & 0.000 \\
\hline $\log D_{\text {subway }}$ & -2.242 & 2.019 & $0.267^{*}$ & -1.609 & 1.987 & $0.418^{*}$ \\
\hline $\log D_{c b d}$ & -3.866 & 1.436 & 0.007 & -2.160 & 1.463 & 0.140 * \\
\hline $\log _{\text {shop }}$ & -7.400 & 1.678 & 0.000 & -5.002 & 1.694 & 0.003 \\
\hline $\log _{\text {park }}$ & -2.097 & 1.926 & $0.277^{*}$ & -1.943 & 1.911 & 0.310 * \\
\hline Log $D_{\text {river }}$ & -0.647 & 2.064 & 0.754 * & -2.090 & 2.040 & $0.306^{*}$ \\
\hline YEAR & 1.257 & 0.162 & 0.000 & 1.301 & 0.160 & 0.000 \\
\hline SCHOOL & & & & 0.886 & 5.486 & 0.872 * \\
\hline $\log D_{\text {factory }}$ & & & & 0.271 & 1.880 & $0.886^{*}$ \\
\hline $\log D_{\text {POP }}$ & & & & 0.074 & 0.012 & 0.000 \\
\hline $\log \mathrm{D}_{\mathrm{JOB}}$ & & & & 0.002 & 0.003 & 0.610 * \\
\hline \multicolumn{7}{|c|}{ Diagnostic information } \\
\hline $\mathrm{R}^{2}$ & 0.761 & & & 0.771 & & \\
\hline Adjusted $\mathrm{R}^{2}$ & 0.759 & & & 0.768 & & \\
\hline $\mathrm{AICc}$ & $15,629.000$ & & & $15,569.000$ & & \\
\hline MSE & 1246.452 & & & 1200.863 & & \\
\hline
\end{tabular}

Notes: $R^{2}, R$ squares; Adjusted $R^{2}$, adjusted $R$ squares; AIC, Akaike information criterion; MSE, mean squared error.

As shown in Table 2, the results, in accordance with reducing the mean square error, show that the performance of the OLS model that incorporates the contextual variables (Model 2) is better than that of the OLS model without the contextual variables (Model 1). Notably, there are slight differences between the models. Regarding the linkages between plot ratio and land price, there is a weak association observed in Model 1, and a significantly negative correlation observed in Model 2 (when the contextual variables are included), which is the same as that of $\log \mathrm{D}_{\text {river }}$. Evaluated as the mean land price and under the two models, residential land price increases significantly with the number of bathrooms.

The effects of $\log \mathrm{D}_{\text {park }}$ and $\log \mathrm{D}_{\text {river }}$ are mainly negative on residential land prices in the study area. According to Model 2, with a reduction in distance to the river or park, residential land price will increase. Proximity to $\log \mathrm{D}_{\mathrm{cbd}}$ and $\log \mathrm{D}_{\text {shop }}$ exerts a direct effect on residential land prices in Model 2. Reducing the distance to the nearest CBD and shopping mall will increase the residential land price significantly.

The estimated coefficient of SCHOOL has a significant impact on residential land prices within the study area, while the proportion of distance to the nearest factory has a positive impact on residential land prices. Overall, either model approximately explains eight-tenths of the variation in residential land prices, with the inclusion of contextual variables giving a better performance. Therefore, the evaluated residential land prices 
can be modeled by the selected housing structural attributes, locational explanatory variables, and neighborhood environment variables. The presumed relationships among the housing structural attributes, locational explanatory and neighborhood environment, and residential land prices are supported by the results of the experiments.

\subsection{Results of the Local Model}

As compared with other GWR-based models, the most significant improvement of the CGTWR model is that it allows the parameter estimates to vary over spatiotemporal location, and produces individual optimal bandwidths for the contextual relationships between the response variable and each predictor variable. It allows the spatial variation of different processes to be modeled at different spatial scales. The units of position and time measurement are actually different. In this study, non-ED metrics were cited in meters and time in years.

The rate of regression weight attenuation near a given point $(u, v, t)$ is determined by the bandwidth in the CGTWR model. One critical issue is the election of spatiotemporal and contextual bandwidth $(B, t, \varsigma)$ to obtain reliable estimates of coefficients $[28,30,52]$. The parameter $\varsigma$ was introduced to offset or reconcile the various spatiotemporal units. Before constructing contextual weighting matrices, these units were unified by computing the spatial and temporal distance. The cross-validation method has been proven to be an effective method for finding ways to eliminate standard errors and deviations [34]. The validation procedure was used in this study to acquire a suitable parameter value in terms of fitting accuracy, with the optimal bandwidth found to be $B=2221, \tau=80,118$, and $\varsigma=216,407$ (Figure 3).

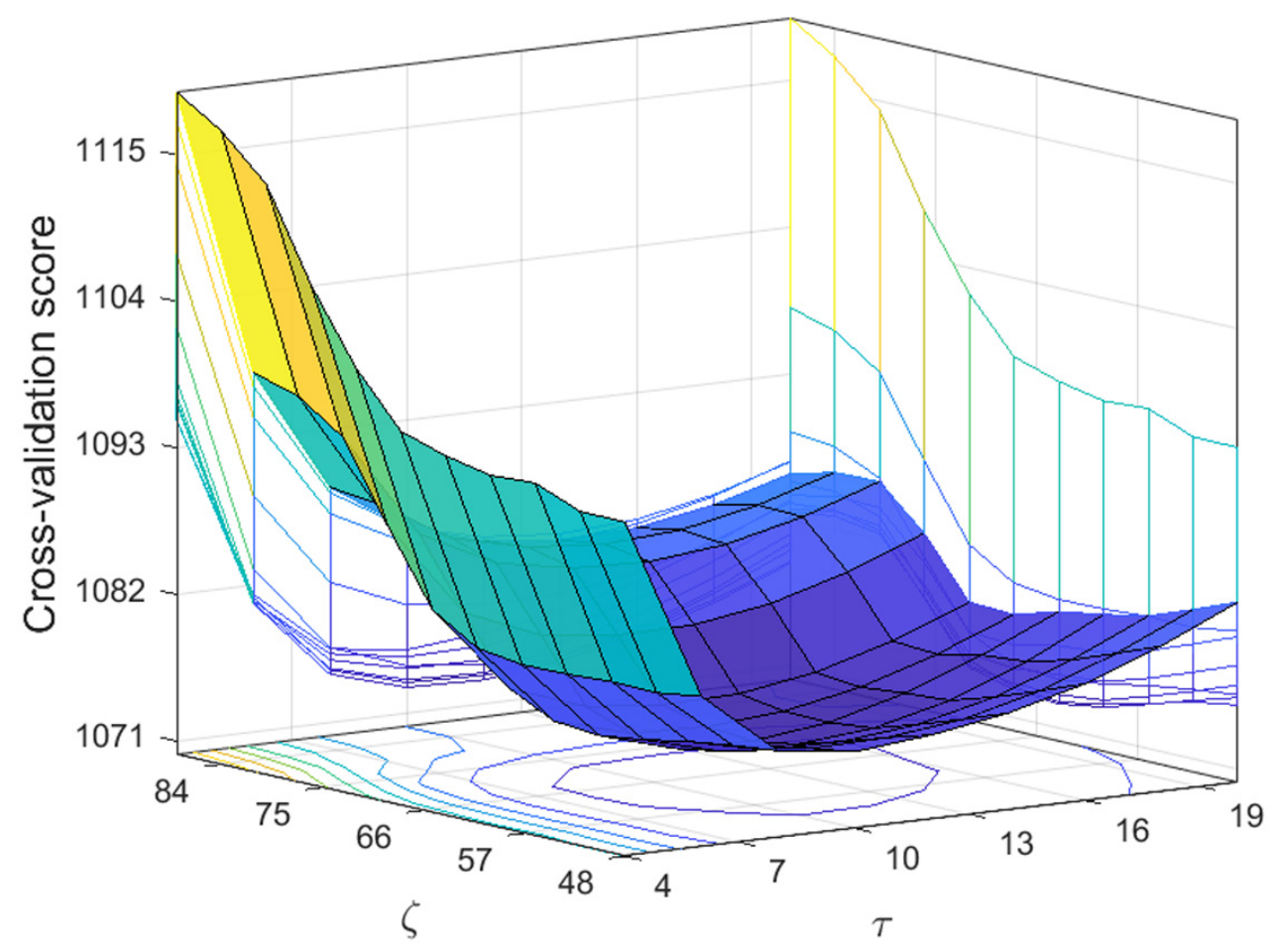

Figure 3. The selection of parameters in the CGTWR model.

The analysis of variance (ANOVA) test $[18,53]$ was adopted to test the significance of the sum of squares from comparisons of the OLS, GWR, CGWR, GTWR, and CGTWR models in Table 3. The residual sum of squares for these models and the improvement of GWR-based models are shown in the first column. The degrees of freedom for each model are listed in the second column. The mean square results of the respective degree of freedom are given in the third column. The F statistic and its corresponding significance level are shown in the fourth and fifth columns, respectively. 
Table 3. ANOVA comparisons among the OLS, GWR, CGWR, GTWR and CGTWR models.

\begin{tabular}{lccccc}
\hline Source of Variation & RSS & DF & MS & $p$ Value & F Value \\
\hline OLS residuals & $3,511,506.98$ & 8.00 & $438,938.37$ & 330.59 & 0.00 \\
GWR residuals & $719,819.36$ & 762.08 & 944.54 & 48.75 & 0.00 \\
CGWR residuals & $649,167.14$ & 743.47 & 873.16 & 33.15 & 0.00 \\
GTWR residuals & $467,541.40$ & 639.07 & 731.60 & 10.58 & 0.00 \\
CGTWR residuals & $399,451.12$ & 628.03 & 636.04 & 9.05 & 0.00 \\
CGWR/GWR improvement & $0.10 \%$ & $0.02 \%$ & $0.08 \%$ & - & - \\
GTWR/GWR improvement & $0.35 \%$ & $0.16 \%$ & $0.23 \%$ & - & - \\
CGTWR/GWR improvement & $0.45 \%$ & $0.18 \%$ & $0.33 \%$ & - & - \\
\hline
\end{tabular}

Notes: The statistically significant values at the $5 \%$ level; RSS, residual sum of squares; DF, degrees of freedom; MS, mean squared error.

The statistics from the ANOVA tests in Table 3 show that there is significant spatiotemporal non-stationarity in SJZ city. Therefore, local models are more suitable for analyzing the dataset in this study area. As compared with the global OLS model, the GWR, CGWR, and GTWR models reduce the residual sum of squares values from 3,511,506.98 to 719,819.36, $649,167.14$, and 467,541.40, respectively, and the CGTWR model generates a considerably lower RSS of 399,451.12. In addition, the MS of the CGTWR model (636.04) is far less than the global model $(438,938.37)$, GWR model (944.54), CGWR model (873.16), and GTWR model (731.60). The CGTWR model with context information is superior to the OLS, GWR, CGWR and GTWR models as evidenced by a lower RSS and MS.

Unlike global models, local models achieve individual parameter estimates at each location. Summaries of local parameter estimates are generated by GWR, CGWR, GTWR, and CGTWR. The minimum (Min), lower quartile (LQ), median (Med), upper quartile (UQ), and maximum (Max) are presented in Tables $4-7$, respectively. The $\mathrm{R}^{2}$, adjusted $\mathrm{R}^{2}$, and AIC statistic are also listed.

Table 4. The distribution of the localized coefficient estimates for the GWR model $(B=2221)$.

\begin{tabular}{|c|c|c|c|c|c|c|c|}
\hline \multicolumn{8}{|c|}{ GWR } \\
\hline Variables & Min & LQ & Med & UQ & Max & $p$ Value & F Value \\
\hline Intercept & -290.876 & -96.802 & -24.21 & 51.612 & 339.021 & 0.002 & 9.565 \\
\hline PlOT & -9.598 & -0.04 & 1.314 & 2.829 & 22.548 & $0.837^{*}$ & 0.042 \\
\hline BATH & -13.122 & 1.791 & 10.722 & 15.785 & 81.652 & 0.030 & 4.698 \\
\hline AREA & 0.708 & 1.709 & 1.839 & 2.014 & 2.228 & 0.000 & 1853.778 \\
\hline $\log _{\text {subway }}$ & -32.905 & -1.794 & 0.402 & 4.44 & 10.283 & 0.198 * & 1.654 \\
\hline $\log D_{C B D}$ & -13.98 & -2.302 & 0.592 & 3.367 & 12.842 & 0.000 & 13.615 \\
\hline LogD & -15.826 & -5.851 & -2.732 & 0.056 & 11.407 & 0.000 & 30.087 \\
\hline LogD park & -32.278 & -9.683 & -0.566 & 6.217 & 30.315 & 0.140 * & 2.173 \\
\hline $\log D_{\text {river }}$ & -25.14 & -5.951 & 0.255 & 4.901 & 34.554 & 0.783 * & 0.076 \\
\hline $\mathrm{R}^{2}$ & 0.85 & & & & & & \\
\hline Adjusted $\mathrm{R}^{2}$ & 0.85 & & & & & & \\
\hline $\mathrm{AICC}$ & $15,322.34$ & & & & & & \\
\hline
\end{tabular}

Table 5. The distribution of the localized coefficient estimates for the CGWR model $(B=2221$ and $\varsigma=216,407)$.

\begin{tabular}{|c|c|c|c|c|c|c|c|}
\hline \multicolumn{8}{|c|}{ CGWR } \\
\hline Variables & Min & LQ & Med & UQ & Max & $p$ Value & F Value \\
\hline Intercept & -312.335 & -99.96 & -22.323 & 55.574 & 494 & 0.001 & 10.617 \\
\hline PlOT & -9.873 & 0.201 & 1.601 & 3.256 & 23.549 & 0.828 * & 0.047 \\
\hline BATH & -23.376 & 0.714 & 10.495 & 15.823 & 84.373 & 0.022 & 5.215 \\
\hline AREA & 0.861 & 1.683 & 1.803 & 1.967 & 2.344 & 0.000 & 2057.813 \\
\hline $\log _{\text {subway }}$ & -35.519 & -1.845 & 0.568 & 4.734 & 10.219 & $0.175^{*}$ & 1.837 \\
\hline $\log D_{\text {CBD }}$ & -10.572 & -2.538 & 0.697 & 3.527 & 13.229 & 0.000 & 15.114 \\
\hline LogD $\mathrm{D}_{\text {shopping }}$ & -15.877 & -5.428 & -2.492 & 0.425 & 11.962 & 0.000 & 33.399 \\
\hline LogD park & -40.692 & -9.599 & -1.199 & 5.704 & 28.474 & 0.120 * & 2.412 \\
\hline$\underset{\mathrm{R}^{2}}{\log \mathrm{D}_{\text {river }}}$ & $\begin{array}{c}-29.566 \\
0.86\end{array}$ & -6.019 & 0.542 & 5.254 & 37.039 & $0.772 *$ & 0.084 \\
\hline Adjusted $\mathrm{R}^{2}$ & 0.86 & & & & & & \\
\hline $\mathrm{AICC}$ & $15,259.77$ & & & & & & \\
\hline
\end{tabular}


Table 6. The distribution of the localized coefficient estimates for the GTWR model $(B=2221$ and $\tau=80,118)$.

\begin{tabular}{cccccccc}
\hline \multicolumn{7}{c}{ GTWR } \\
\hline Variables & Min & LQ & Med & UQ & Max & $p$ Value & F Value \\
\hline Intercept & -318.933 & -65.66 & 2.642 & 58.118 & 425.358 & 0.000 & 14.726 \\
PlOT & -29.568 & -1.91 & 0.656 & 3.453 & 16.852 & $0.799 *$ & 0.065 \\
BATH & -46.788 & -2.679 & 13.601 & 25.134 & 130.518 & 0.007 & 7.233 \\
AREA & 0.097 & 1.281 & 1.536 & 1.795 & 2.942 & 0.000 & 2854.048 \\
LogD & -37.534 & -3.034 & 0.256 & 4.219 & 37.555 & $0.110^{*}$ & 2.547 \\
LogD $D_{\text {CBD }}$ & -21.974 & -2.255 & 0.487 & 3.009 & 17.697 & 0.000 & 20.962 \\
LogD $D_{\text {shopping }}$ & -26.48 & -7.494 & -2.819 & 1.75 & 17.629 & 0.000 & 46.322 \\
LogD $_{\text {park }}$ & -40.117 & -7.183 & -0.943 & 5.64 & 40.797 & $0.067 *$ & 3.345 \\
LogD $_{\text {river }}$ & -36.415 & -6.041 & 0.166 & 5.166 & 80.012 & $0.733 *$ & 0.116 \\
$\mathrm{R}^{2}$ & 0.90 & & & & & & \\
Adjusted $\mathrm{R}^{2}$ & 0.90 & & & & & & \\
$\mathrm{AICC}$ & $15,225.56$ & & & & & &
\end{tabular}

Table 7. The distribution of the localized coefficient estimates for the CGTWR model $(B=2221$, $\tau=80,118$, and $\varsigma=216,407)$.

\begin{tabular}{|c|c|c|c|c|c|c|c|}
\hline \multicolumn{8}{|c|}{ CGTWR } \\
\hline Variables & Min & LQ & Med & UQ & Max & $p$ Value & F Value \\
\hline Intercept & -455.092 & -68.178 & 2.916 & 55.817 & 381.896 & 0.000 & 17.255 \\
\hline PlOT & -28.392 & -1.726 & 0.867 & 3.814 & 17.659 & $0.782 *$ & 0.076 \\
\hline BATH & -47.745 & -2.163 & 14.292 & 26.304 & 135.756 & 0.004 & 8.476 \\
\hline AREA & 0.005 & 1.272 & 1.508 & 1.763 & 2.914 & 0.000 & 3344.251 \\
\hline $\log D_{\text {subway }}$ & -37.153 & -2.961 & 0.367 & 4.271 & 34.581 & 0.084 * & 2.985 \\
\hline $\log D_{C B D}$ & -20.187 & -2.329 & 0.683 & 3.361 & 19.615 & 0.000 & 24.562 \\
\hline Log $\mathrm{D}_{\text {shopping }}$ & -25.717 & -7.126 & -2.644 & 1.77 & 15.428 & 0.000 & 54.278 \\
\hline $\log D_{\text {park }}$ & -44.432 & -7.276 & -1.445 & 5.509 & 57.899 & $0.052 *$ & 3.920 \\
\hline Log $D_{\text {river }}$ & -37.176 & -6.12 & 0.396 & 5.129 & 82.746 & $0.712 *$ & 0.136 \\
\hline $\mathrm{R}^{2}$ & 0.92 & & & & & & \\
\hline Adjusted $\mathrm{R}^{2}$ & 0.91 & & & & & & \\
\hline $\mathrm{AICc}$ & $15,179.84$ & & & & & & \\
\hline
\end{tabular}

Tables 4-7 provide the detailed statistical comparisons. The AIC value of the models decreased from 15,322.34 in the GWR model, to 15,259.77 in the CGWR model, 15,225.56 in the GTWR model, and 15,179.84 in the CGTWR model. By comparing the $\mathrm{R}^{2}$ values, the CGWR model significantly improved the $\mathrm{R}^{2}$ value to 0.86 , indicating that adding contextual variables to the analysis by adjusting the geographical weights matrix outperformed the GWR model. Moreover, the CGTWR model, which considered contextual information, yielded a $92 \%$ improvement over the GTWR model. Thus, it should be noted that the CGTWR model, using the sample data, could effectively address spatiotemporal heterogeneity, and could creatively extend the feasibility of importing the contextualization into the GTWR model.

The abundant information generated by local models presents a challenge for displaying the results. Since the CGTWR model is more effective than the GTWR model and CGTWR achieves a similar performance to CGWR, we only focused on the local estimates of CGTWR. CGTWR generates local parameter estimates that reflect possible spatiotemporal and contextual heterogeneity in the processes affecting residential land price. The CGTWR model's performance and its spatiotemporal non-stationarity were explored visually by mapping the local coefficient estimates of the variables. Figure $4 a-h$ presents the spatial pattern of the CGTWR model estimated coefficients. 

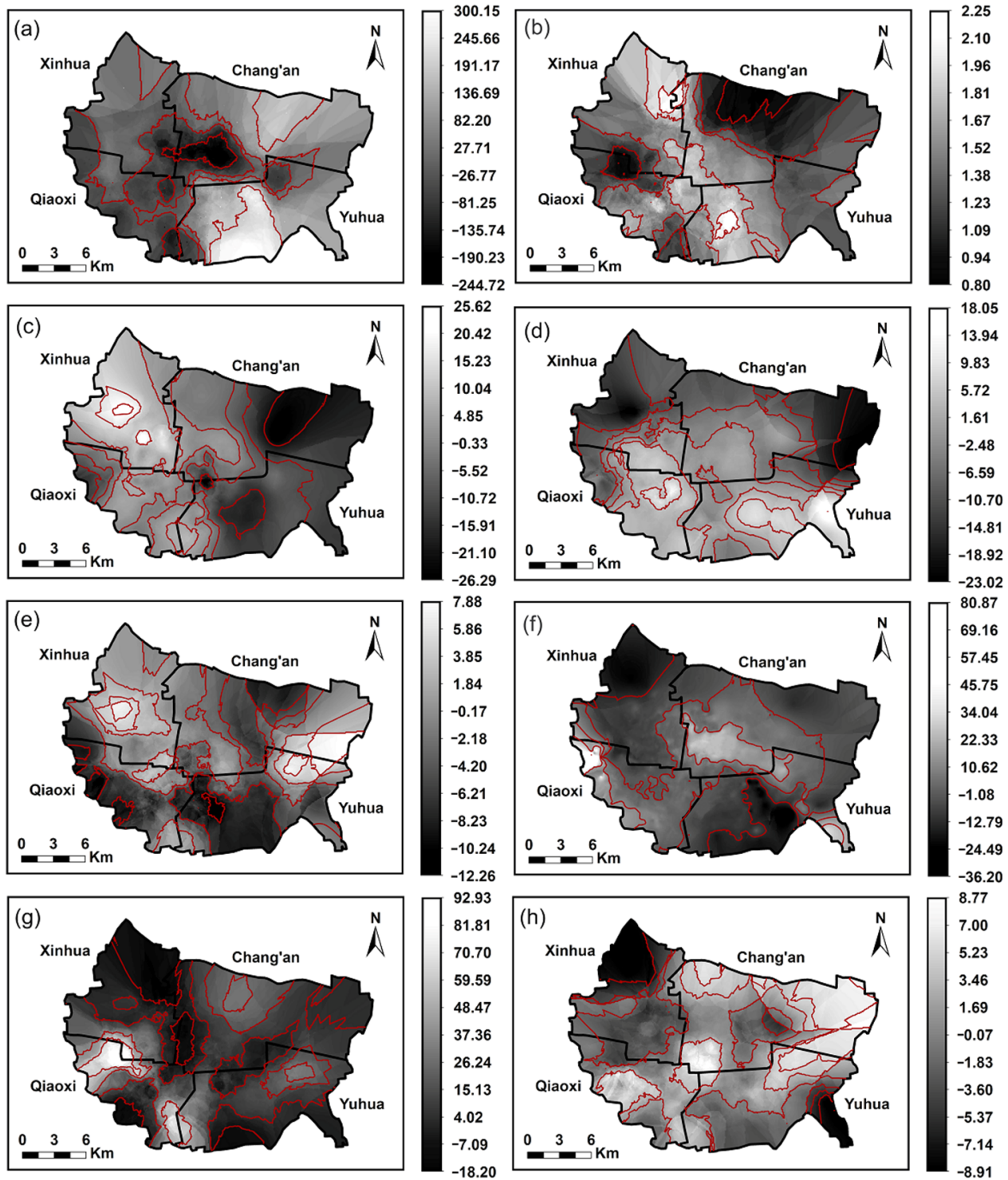

Figure 4. Spatial mapping for: (a) coefficients of intercept; (b) total floor area; (c) proximity of the nearest park; (d) proximity of the nearest transport facility; (e) proximity of the nearest central shopping plaza; (f) proximity of the nearest river; (g) total number of bathrooms; (h) proximity of the nearest central business district, by contextualized geographically and temporally weighted regression modeling.

The results suggest that AREA is positively correlated with residential land prices, as shown in Table 7. In other words, the larger the living area is, the higher the residential land price is (Figure $4 \mathrm{~b}$ ). The effects of $\log \mathrm{D}_{\text {park }}$ changes from positive in the northwest to negative in the southeast. This is reasonable since the Xinhua district is located in three parks, i.e., Xiushui Park, Yulin Park, and Qiushi Park, which increases coefficient values on parks (Figure $4 \mathrm{c}$ ). The spatial variation of $\log \mathrm{D}_{\text {subway }}$ in the CGTWR model varies from high in the inner zone near metro lines to low in the external zones over this study area (Figure 4d). This is consistent with the distribution of the Shijiazhuang Metro Lines 1, 2, and 3.

\section{Discussion and Policy Implications}

\subsection{The Performance of the Model in Exploring Spatiotemporal Heterogeneity}

The aim of exploring spatiotemporal heterogeneity of residential land prices was to provide appropriate guidance to strengthen classified regulation and control of the 
real estate market. Furthermore, we should take measures to protect the environment from further deterioration under the rapid acceleration of urbanization. In this study, we develop the CGTWR method, which extends the definition of proximity to include geographical location, temporal information, and contextual attributes by incorporating contextual attribution into the GTWR weights matrix. Furthermore, the method focuses on the construction of a spatiotemporal and contextual weights matrix for a hierarchical dataset as opposed to a spatiotemporal matrix. In other words, the CGTWR gives the greatest weight to points that are both proximate and situated in the same or similar neighborhood types by adjusting the spatiotemporal weights.

The results from Tables 3-7 justify considering the added complexity of the CGTWR model; it still performs better than the OLS, GWR, CGWR, and GTWR models. By incorporating contextual information in the GTWR, there are substantial benefits. The GWR, CGWR, GTWR, and CGTWR models reduce the residual sum of squares by $79.5 \%, 81.5 \%$, $86.7 \%$ and $88.6 \%$, respectively, as compared with a global ordinary least squares model. More importantly, the CGWR and CGTWR significantly improve the $\mathrm{R}^{2}$ values to 0.86 and 0.92, respectively, indicating that models considering contextual information outperform GWR and GTWR models. In addition, the $\mathrm{R}^{2}$ values between the GTWR and CGTWR modles, taking into consideration temporal variation, yield $90 \%$ and $92 \%$ improvement, respectively, over the GWR and CGWR models. The CGTWR model using sample data effectively addresses spatiotemporal heterogeneity, and creatively extends the feasibility of importing the contextualization into the GTWR model.

Some limitations still remain in our analysis and further research is needed. There were only 913 housing data available. Inadequate information can be expected to influence the model's performance. Further investigation of the performance of the CGTWR model with more effective data would be worthwhile. Furthermore, the simple weighting system based on a linear combination of spatiotemporal and contextual distances was used. In addition, we used a simple weighted system based on a linear combination of space time and context distance. In order to produce better results, more effective weightings need to be designed. Although the contextual variables are used within the weight's matrix, no estimate of the effect of each contextual variable upon the response variable was determined. The contextual variables adjust the weights matrix but, aside from this, have no explanatory or predictive role within the model. We are devoted to developing this model into free software to assist with understanding the trends of residential land price and the patterns of urban expansion.

\subsection{The Impact Factors of Policy Driven by Residential Land Prices}

The results of our analyses indicate that contextual explanatory variables including school district, proximity to industrial zone, population density, and job density all have an impact on residential land prices. Notably, we further distinguished linkages between school district and industrial zone factors and residential land prices under the influence of Chinese policy. From the perspective of educational reform, the policy of district correspondence enrolment was first adopted in 1986 [54,55]. The purpose was to ensure equal access to public education resources, and to improve the fairness of the admission process. Residential areas were divided into designated school districts corresponding to nearby public primary and junior middle schools, and it was specified that children living in neighborhoods of school districts were required to enroll in the corresponding schools [56-58]. However, houses in school districts have gradually become a manifestation of capitalization for public goods, i.e., the precious popularity of school district housing in China, where the quality of public schools is higher $[59,60]$.

Under the strict enforcement policy, Chinese parents are willing to pay higher prices for residential land so that their children can enroll in schools with higher quality teaching. The average price of residential land in school districts over the study area was $1,711,954.55$ yuan $(\approx 264,325.78$ USD), which was $14.64 \%$ higher than the average values of all house types (Table 1). It is worth noting that a school may serve several communities, 
where the residential land prices decrease with increasing distance to the school. This is likely to be caused by school quality, where higher quality schools result in significantly higher residential land prices than other schools. The two popular schools in Figure 4 were selected to be typical cases that all had high-quality and expensive homes in their district. Linyin Dayuan is a house in the Hezuolu Primary School District, which has a price $34.18 \%$ higher than the residential land prices at Zhongxiu Garden just across the road. The housing within the foreign language school district, Fuqiang Power District, is $35.42 \%$ higher than the residential land prices of Qingyuan District, while the structure of the houses is similar, and the distance between the houses is relatively close. Figure 5 clearly shows the capitalization effect of public-school quality on residential land prices in urban areas through the visual distribution of residential land prices.

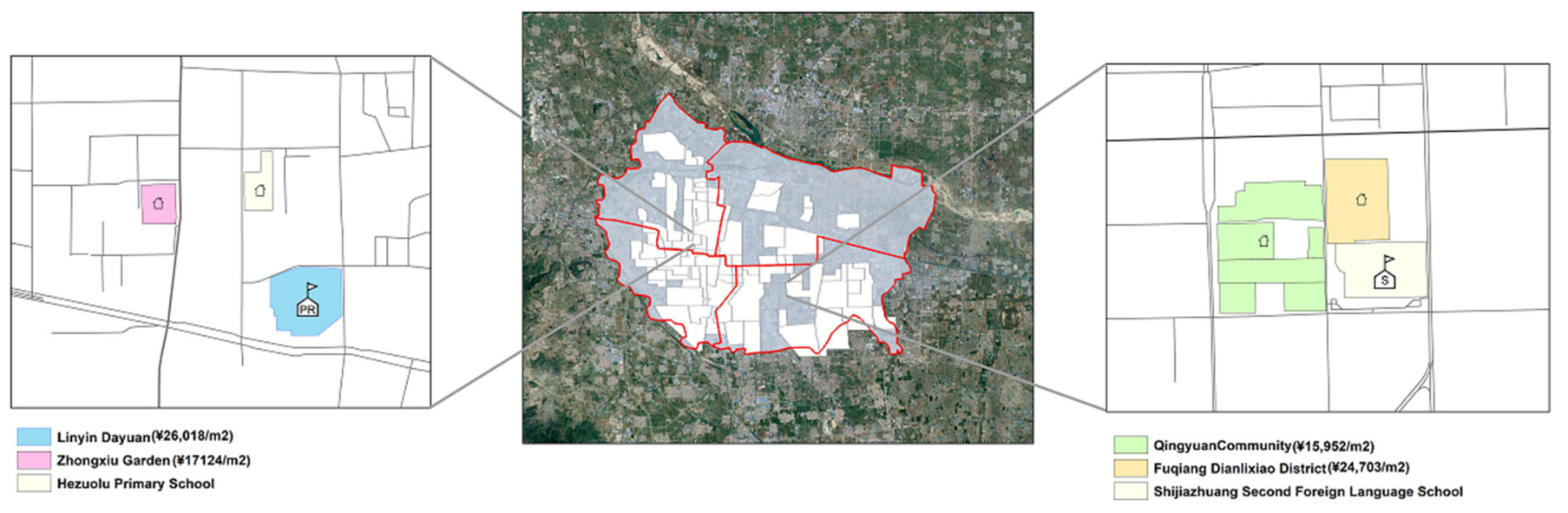

Figure 5. Special samples illustrating the residential land prices of school districts.

From the perspective of industrial reform, SJZ city was viewed as a major construction project during China's First Five-Year Plan in 1953 [61,62]; numerous factories including textile, chemical, pharmaceutical, steel, and machinery factories were set up with the support of national policies. Under the implementation of the Reform and Opening up Policy, the city's rate of GDP increment was approximately 71.66\% from 1953 to 1984 according to the Shijiazhuang Industry and Information Bureau. The quantity of enterprise has expanded rapidly, and the business scale has enlarged continuously with diversified product features $[38,63,64]$. SJZ city has become a crucial industrial town in China over the last several decades due to its industrial system with reasonable layout, complete structure, and strong comprehensive strength. However, the problem of environmental pollution in this city has become increasingly prominent, and has begun to cause negative effects for some factories with the development of urban construction and the economy framework [65,66]. In 2018, the municipal government issued policies to relocate and transform polluting industrial enterprises in the main urban areas. If these enterprises fail to complete the relocation as planned, they will be forced to close down in accordance with the regulations and law.

Under the series of policies on industrial land allocation, many industrial factories have gradually moved out of the four main urban areas. The remainder is mainly divided into seven factories including chemical, steel, paint, machinery, food, electrochemical, and pharmaceutical factories. However, some factories also cause water and air pollution from industrial solid waste due to their inadequate management, for example, the iron and steel plant located in the east of the Chang'an District creates industrial dust that has a deleterious effect on the surrounding environment and the sound of the factory operation has seriously affected the work and lives of nearby residents (Figure 6b). The chlorine leakage accident that occurred in the electrochemical plant, resulted in dozens of losses in the surrounding vegetable fields acres (Figure $6 \mathrm{~g}$ ). Furthermore, the first food factory was exposed because a nearby dweller could smell something peculiar in the well water 
due to leakage of a benzene distillate storage tank in the factory (Figure 6h). Therefore, the distance to factories is the main factor affecting residential land prices. However, regarding industrial zone factors, there is a positive correlation between $\log \mathrm{D}_{\text {factory }}$ and residential land prices, since the coefficients of $\log D_{\text {factory }}$ were positive. The closer the houses are to the factory, the more sensitive the house values are to these attributes, that is to say, the same amount of change in these attributes (ceteris paribus) will bring a larger change in house values for houses located near the factory as compared with those located farther away.
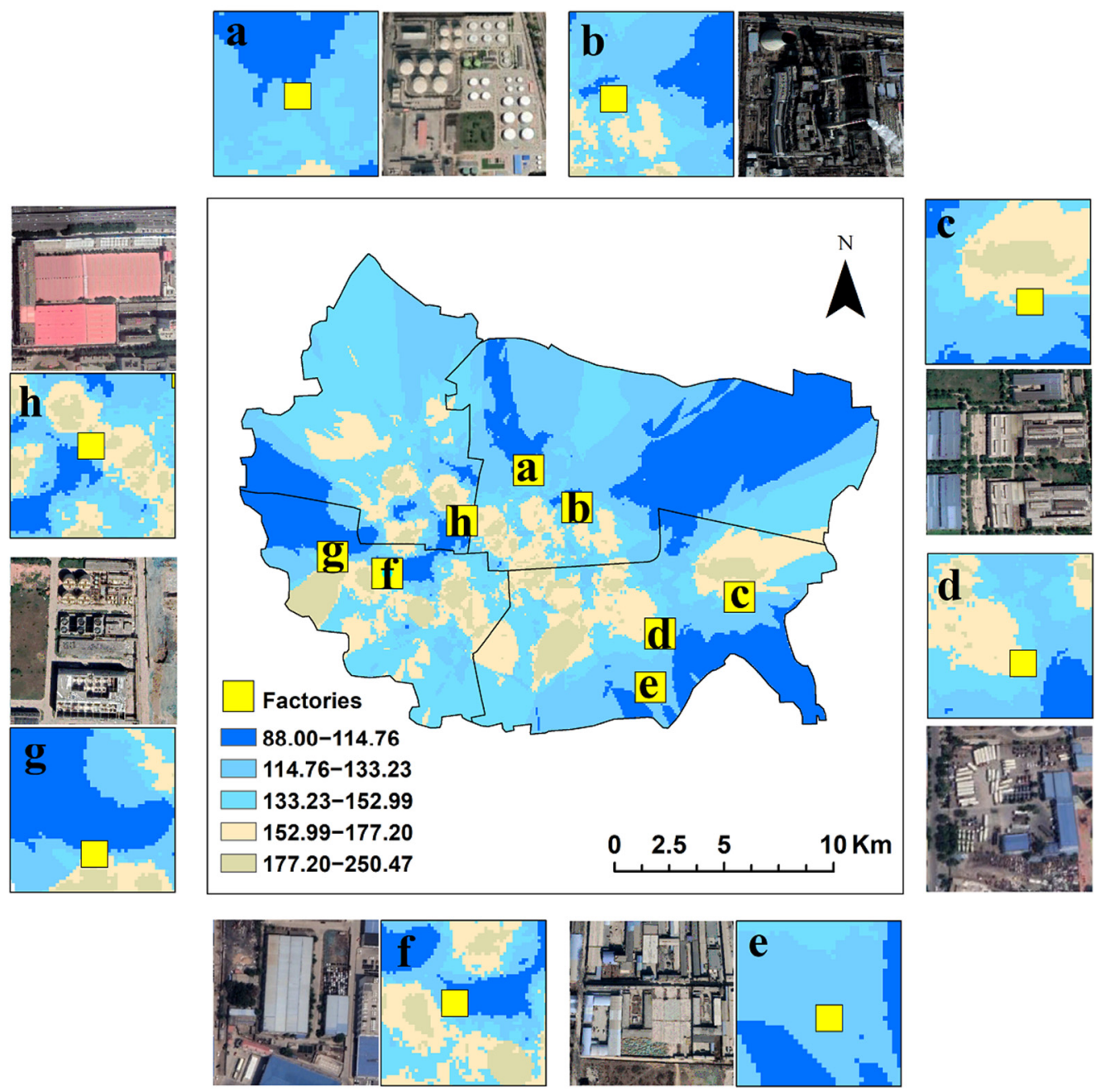

Figure 6. Examples of factories: (a) Chemical factory; (b) steel factory; (c) pharmaceutical factory; (d) building materials factory; (e) machinery factory; (f) paint factory; (g) electrochemical plant; (h) food factory.

\section{Conclusions}

In this study, the contextualized geographically and temporally weighted regression (CGTWR) model was outlined and applied to a case study of residential land price values in SJZ city, China. The analysis revealed that global and local regression models were customized to explain some types of phenomena: the OLS model adapts to global uniform variation, the GWR model accommodates single spatial heterogeneity, the CGWR model contributes to the effect of contextual attributes, and the GTWR model applies to spatiotemporal non-stationarity. The CGTWR model upgraded the spatiotemporal kernel to a context-adjustable kernel and completed the neighborhood-level information for the GTWR model. 
The GWR-based models (GWR, CGWR, GTWR and CGTWR) all provided significant improvements in terms of $\mathrm{R}^{2}$ and AIC measures as compared with the OLS model. The empirical results suggest that the traditional distance weights matrix of GTWR with a measure of contextual difference in CGTWR appears to be justified since the residual sum of squares is significantly reduced and the contextual and spatiotemporal non-stationarity are considered. Moreover, we applied the non-ED metric to locational explanatory variables in order to overcome the inaccurate coefficient estimation of Euclidean distance (ED) measurement and the misinterpreted spatial pattern in estimation due to linear measurement. The CGTWR model using sample data could effectively address spatiotemporal heterogeneity, and could creatively explore the feasibility of importing the contextualization into the GTWR model.

Meanwhile, the empirical research proves that floor area, building age, transport facility, school district, and proximity to an industrial zone all have significant effects on residential land prices in SJZ city. Notably, the relationships between school district and industrial zone factors and real estate were analyzed under the influence of Chinese policy. With the continuous development of economy and technology, Chinese parents have attached significant importance to their children's education and are willing to pay higher prices for residential land so that their children can enroll in better schools. Houses in school districts have gradually become a manifestation of capitalization for public goods, i.e., the precious popularity of school district housing in China, where the quality of public schools is higher. Several social problems may arise due to the high price of housing in school districts, such as unfair educational opportunities, social stratification, and speculative trading. The government should carry out institutional reform to ensure adequate educational funds, equalize access to public educational resources, and enhance fairness in the enrollment process.

Furthermore, under the rapid urbanization process, the problem of environmental pollution in SJZ city has become increasingly prominent, and has begun to manifest as negative effects of some factories on the contextual environment. The experimental results show that there is a positive correlation between $\log \mathrm{D}_{\text {factory }}$ and residential land price, that is, the closer the distance to the factory, the lower the residential land price. The government could consider rationally adjusting the industrial structure, comprehensively planning urban construction, and rationally arranging industrial distribution. Overall, the CGTWR model provides a supplementary effective methodology for large-scale estimation of residential land price and supplies evidence for policy makers to understand the nature of varying relationships within a house price dataset in China.

Author Contributions: Conceptualization, Z.C. and Y.Y.; methodology, Z.C., Y.Y., Y.Z. and Y.F.; writing—original draft preparation, Z.C.; writing—review and editing, Z.C., Y.Y., Y.Z., Y.F. and L.H. funding acquisition, Y.Y., Y.Z. and L.H. All authors have read and agreed to the published version of the manuscript.

Funding: This research was funded by the National Natural Science Foundation of China, grant no. 41801316; the National Natural Science Foundation of China, grant no. 42071384; the National Natural Science Foundation of China, grant no. 42001343; University Philosophy and Social Science Research Funds in Jiangsu Province of China: 2021SJA1716; The Project of Water Conservancy in Jiangsu Province of China: 2020058; and the Youth Fund of Jiangsu Meteorological Bureau, grant no. Q201708.

Institutional Review Board Statement: Not applicable.

Informed Consent Statement: Not applicable.

Data Availability Statement: The data presented in this study are available on request from the corresponding author.

Conflicts of Interest: The authors declare no conflict of interest. 


\section{References}

1. Dunsky, R.M.; Follain, J.R.; Giertz, S.H. Pricing Credit Risk for Mortgages: Credit Risk Spreads and Heterogeneity across Housing Markets. Real Estate Econ. 2021, 21, 997-1032. [CrossRef]

2. Stockhammer, E.; Bengtsson, E. Financial effects in historic consumption and investment functions. Int. Rev. Appl. Econ. 2020, 34, 304-326. [CrossRef]

3. Qu, Y.B.; Jiang, G.H.; Li, Z.T.; Shang, R.; Zhou, D.Y. Understanding the multidimensional morphological characteristics of urban idle land: Stage, subject, and spatial heterogeneity. Cities 2020, 97, 102492. [CrossRef]

4. Cabras, I.; Sohns, F.; Canduela, J.; Toms, S. Public houses and house prices in Great Britain: A panel analysis. Eur. Plan. Stud. 2020, 29, 163-180. [CrossRef]

5. Solar, P.M. China's GDP: Some Corrections and the Way Forward. J. Econ. Hist. 2021, 81, 943-957. [CrossRef]

6. Gong, P.; Liang, S.; Carlton, E.J.; Jiang, Q.W.; Wu, J.Y.; Wang, L.; Remais, J.V. Urbanisation and health in China. Lancet 2012, 379, 843-852. [CrossRef]

7. Harten, J.G.; Kim, A.M.; Brazier, J.C. Real and fake data in Shanghai's informal rental housing market: Ground truthing data scraped from the internet. Urban Stud. 2021, 58, 1831-1845. [CrossRef]

8. Schneider, A.; Woodcock, C.E. Compact, Dispersed, Fragmented, Extensive? A Comparison of Urban Growth in Twenty-five Global Cities using Remotely Sensed Data, Pattern Metrics and Census Information. Urban Stud. 2014, 45, 659-692. [CrossRef]

9. Alm, J.; Lai, W.Z.; Li, X. Housing market regulations and strategic divorce propensity in China. J. Popul. Econ. 2021, 25, 1-29.

10. Hussain, T.; Abbas, J.; Wei, Z.; Ahmad, S.; Bai, X.H. Impact of Urban Village Disamenity on Neighboring Residential Properties: Empirical Evidence from Nanjing through Hedonic Pricing Model Appraisal. Urban Plan. Dev. 2020, 147, 04020055. [CrossRef]

11. Seo, B.K.; Park, G.R. Food insecurity and housing affordability among low-income families: Does housing assistance reduce food insecurity? Public Health Nutr. 2021, 24, 4339-4345. [CrossRef]

12. Gao, Y.Y.; Zang, L.Z.; Sun, J. Does Computer Penetration Increase Farmers' Income? An Empirical Study from China. Telecommun. Policy 2018, 42, 345-360. [CrossRef]

13. Cheung, K.S.; Wong, S.K. Entry and Exit Affordability of Shared Equity Homeownership: An International Comparison. Soc. Sci. Electron. Publ. 2020, 13, 737-752. [CrossRef]

14. Wallner, R. GIS measures of residential property views. J. Real Estate Lit. 2014, 20, 224-225. [CrossRef]

15. Sesli, F.A. Creating real estate maps by using GIS: A case study of Atakum Samsun/Turkey. Acta Montan. Slovaca 2015, 20, 260-270.

16. Morano, P.; Tajani, F.; Locurcio, M. GIS application and econometric analysis for the verification of the financial feasibility of roof-top wind turbines in the city of Bari (Italy). Renew. Sustain. Energy Rev. 2017, 70, 999-1010. [CrossRef]

17. Chmielewska, A.; Adamiczka, J.; Romanowski, M. Genetic Algorithm as Automated Valuation Model Component in Real Estate Investment Decisions System. Real Estate Manag. Valuat. 2020, 28, 1-14. [CrossRef]

18. Jacquet-Lagreze, E.; Siskos, J. Assessing a set of additive utility functions for multicriteria decision-making, the UTA method. Eur. J. Oper. Res. 1982, 10, 151-164. [CrossRef]

19. Morano, P.; Tajani, F.; Locurcio, M. Multicriteria analysis and genetic algorithms for mass appraisals in the Italian property market. Int. J. Hous. Mark. Anal. 2018, 11, 229-262. [CrossRef]

20. Guarini, M.R.; Locurcio, M.; Battisti, F. GIS-Based Multi-criteria Decision Analysis for the "Highway in the Sky". International Conference on Computational Science and Its Applications. Springer Int. Publ. 2015, 9157, 146-161.

21. Dong, S.H.; Wang, Y.D.; Gu, Y.Y.; Shao, S.W.; Liu, H.; Wu, S.M.; Li, M.M. Predicting the turning points of housing prices by combining the financial model with genetic algorithm. PLOS ONE 2020, 15, 457-461. [CrossRef]

22. Ahn, J.J.; Byun, H.W.; Oh, K.J.; Kim, T.Y. Using ridge regression with genetic algorithm to enhance real estate appraisal forecasting. Expert Syst. Appl. 2012, 39, 8369-8379. [CrossRef]

23. Brunsdon, C.; Fotheringham, A.S.; Charlton, M.E. Geographically Weighted Regression: A Method for Exploring Spatial Nonstationarity. Geogr. Anal. 1996, 28, 281-298. [CrossRef]

24. Brunsdon, C.; Fotheringham, A.S.; Charlton, M.E. Spatial Nonstationarity and Autoregressive Models. Environ. Plan. A 1998, 30, 957-973. [CrossRef]

25. Harris, P.; Fotheringham, A.S.; Crespo, R. The Use of Geographically Weighted Regression for Spatial Prediction: An Evaluation of Models Using Simulated Data Sets. Math. Geosci. 2010, 42, 657-680. [CrossRef]

26. Brunsdon, C.; Fotheringham, A.S.; Charlton, M.E. Some Notes on Parametric Significance Test for Geographically Weighted Regression. J. Reg. Sci. 1999, 39, 497-524. [CrossRef]

27. Habib, M.; Miller, E. Influence of Transportation Access and Market Dynamics on Property Values: Multilevel Spatiotemporal Models of Housing Price. Transp. Res. Rec. J. Transp. Res. Board 2008, 2076, 183-191. [CrossRef]

28. Huang, B.; Wu, B.; Barry, M. Geographically and temporally weighted regression for modeling Spatio-temporal variation in house prices. Int. J. Geogr. Inf. Sci. 2010, 24, 383-401. [CrossRef]

29. Fotheringham, A.S.; Kelly, M.H.; Charlton, M. The demographic impacts of the Irish famine: Towards a greater geographical understanding. Trans. Inst. Br. Geogr. 2013, 38, 221-237. [CrossRef]

30. Harris, R.; Dong, G.; Zhang, W. Using contextualized Geographically Weighted Regression to model the spatial heterogeneity of land prices in Beijing, China. Trans. GIS 2013, 17, 901-919. [CrossRef] 
31. Beracha, E.; Gilbert, B.T.; Kjorstad, T. On the Relation between Local Amenities and House Price Dynamics. Real Estate Econ. 2018, 46, 612-654. [CrossRef]

32. Abidoye, R.B.; Chan, A.P.C. Improving property valuation accuracy: A comparison of hedonic pricing model and artificial neural network. Pac. Rim Prop. Res. J. 2018, 24, 71-83. [CrossRef]

33. Weir, R. Using geographically weighted regression to explore neighborhood-level predictors of domestic abuse in the UK. Trans. GIS 2019, 23, 1232-1250. [CrossRef]

34. Baborska-Narozny, M.; Stevenson, F.; Chatterton, P. Temperature in housing: Stratification and contextual factors. Proc. Inst. Civ. Eng. Eng. Sustain. 2015, 169, 125-137. [CrossRef]

35. Weimer, D.L.; Wolkoff, M.J. School Performance and Housing Values: Using Non-Contiguous District and Incorporation Boundaries to Identify School Effects. Natl. Tax J. 2001, 54, 231-253. [CrossRef]

36. Bates, L.K. Does Neighborhood really matter? Comparing historically defined neighborhood boundaries with housing submarkets. J. Plan. Educ. Res. 2006, 26, 5-17. [CrossRef]

37. Fontes, T.; Li, P.L.; Barros, N.; Zhao, P.J. Trends of PM2.5 concentrations in China: A long term approach. J. Environ. Manag. 2017, 196, 719-732. [CrossRef] [PubMed]

38. Majeed, H. Consideration of local geographical variations in PM2.5 concentrations in China. Lancet Public Health 2014, 3, 564. [CrossRef]

39. Kim, Y.; Kim, J.Y.; Lee, S.B.; Moon, K.C.; Bae, G.N. Review on the Recent PM2.5 Studies in China. J. Korean Soc. Atmos. Environ. 2015, 31, 411-429. [CrossRef]

40. Apte, J.S.; Marshall, J.D.; Cohen, A.J.; Brauer, M. Addressing Global Mortality from Ambient PM2.5. Environ. Sci. Technol. 2015, 49, 8057-8066. [CrossRef]

41. Gao, A.F.; Wang, J.Y.; Luo, J.F.; Li, A.G.; Chen, K.Y.; Wang, P.F.; Wang, Y.Y.; Li, J.Y.; Hu, J.L.; Zhang, H.L. Temporal variation of PM 2.5-associated health effects in Shijiazhuang, Hebei. Front. Environ. Sci. Eng. 2021, 15, 82. [CrossRef]

42. Rosen, S. Hedonic prices and implicit markets: Product differentiation in pure competition. J. Political Econ. 1974, 82, 34-55. [CrossRef]

43. Mian, A.; Sufi, A. House Prices, Home Equity-Based Borrowing, and the U.S. Household Leverage Crisis. Am. Econ. Rev. 2009, 101, 2132-2156. [CrossRef]

44. Lisi, G. Hedonic pricing models and residual house price volatility. Lett. Spat. Resour. Sci. 2019, 12, 133-142. [CrossRef]

45. Liu, J.; Yang, Y.; Xu, S.; Zhao, Y.; Wang, Y.; Zhang, F. A Geographically Temporal Weighted Regression Approach with Travel Distance for House Price Estimation. Entropy 2016, 18, 303. [CrossRef]

46. Cossu, L.; Zanardo, P.; Zannier, U. Products of elementary matrices and non-Euclidean principal ideal domains. J. Algebra 2018, 501, 182-205. [CrossRef]

47. Anderson, M.J. Distance-Based Tests for Homogeneity of Multivariate Dispersions. Biometrics 2006, 62, 245-253. [CrossRef] [PubMed]

48. Abbas, K.; Liu, M.; Venkatesh, M.; Amico, E.; Kaplan, A.D.; Ventresca, M.; Pessoa, L.; Harezlak, J.; Goñi, J. Geodesic distance on optimally regularized functional connectomes uncovers individual fingerprints. Brain Connect. 2021, 11, 333-348. [CrossRef] [PubMed]

49. Disatnik, D.; Sivan, L. The multicollinearity illusion in moderated regression analysis. Mark. Lett. 2016, 27, 403-408. [CrossRef]

50. Hong, Z.; Mei, C.; Wang, H.; Du, W. Spatiotemporal effects of climate factors on childhood hand, foot, and mouth disease: A case study using mixed geographically and temporally weighted regression models. Int. J. Geogr. Inf. Sci. 2021, 35, 1611-1633. [CrossRef]

51. Guo, B.; Wang, X.; Pei, L.; Su, Y.; Zhang, D.; Wang, Y. Identifying the spatiotemporal dynamic of PM2.5 concentrations at multiple scales using geographically and temporally weighted regression model across China during 2015-2018. Sci. Total Environ. 2020, 751, 141765. [CrossRef]

52. Fotheringham, A.S.; Crespo, R.; Yao, J. Geographical and Temporal Weighted Regression (GTWR). Geogr. Anal. $2015,47,431-452$. [CrossRef]

53. Meagan, C.; Gordon, M. Using Geographically Weighted Regression to Explore Local Crime Patterns. Soc. Sci. Comput. Rev. 2007, 25, 174-193.

54. McMillen, D.P. Geographically Weighted Regression: The Analysis of Spatially Varying Relationships. Am. J. Agric. Econ. 2004, 86, 554-556. [CrossRef]

55. Hudson, C. Governing the governance of education: The state strikes back? Eur. Educ. Res. J. 2007, 6, 266-282. [CrossRef]

56. Portz, J. “Next-Generation” Accountability? Evidence From Three School Districts. Urban Educ. 2017, 56, 1297-1327. [CrossRef]

57. Clapp, J.M.; Nanda, A.; Ross, S.L. Which school attributes matter? The influence of school district performance and demographic composition on property values. J. Urban Econ. 2008, 63, 451-466. [CrossRef]

58. Hooge, E.H.; Moolenaar, N.M.; Look, K.; Janssen, S.K.; Sleegers, P. The role of district leaders for organization social capital. J. Educ. Adm. 2019, 57, 296-316. [CrossRef]

59. Zhang, J.; Li, H.; Lin, J.; Zheng, W.; Li, H.; Chen, Z. Meta-analysis of the relationship between high quality basic education resources and housing prices. Land Use Policy 2020, 99, 104843. [CrossRef]

60. Huang, B.; He, X.; Xu, L.; Zhu, Y. Elite school designation and housing prices-quasi-experimental evidence from Beijing, Chinas. J. Hous. Econ. 2020, 50, 101730. [CrossRef] 
61. Thomas, S.; Chen, J. Reforming China's Financial Markets. Curr. Hist. 2001, 100, 291-294. [CrossRef]

62. Alder, S.; Shao, L.; Zilibotti, F. Economic reforms and industrial policy in a panel of Chinese cities. J. Econ. Growth 2013, 21, 305-349. [CrossRef]

63. Bocken, N.; Pauw, I.; Bakker, C.; Grinten, B. Product design and business model strategies for a circular economy. J. Ind. Prod. Eng. 2016, 33, 308-320. [CrossRef]

64. Urbinati, A.; Franzo, S.; Chiaroni, D. Enablers and Barriers for Circular Business Models: An empirical analysis in the Italian automotive industry. Sustain. Prod. Consum. 2021, 27, 551-566. [CrossRef]

65. Grislain-Letrémy, C.; Katossky, A. The impact of hazardous industrial facilities on housing prices: A comparison of parametric and semiparametric hedonic price models. Reg. Sci. Urban Econ. 2014, 49, 93-107. [CrossRef]

66. Wang, C.; Hui, F.; Wang, Z.; Zhu, X.; Zhang, X. Chemical characteristics of size-fractioned particles at a suburban site in Shijiazhuang, North China: Implication of secondary particle formation-ScienceDirect. Atmos. Res. 2021, 259, 80-90. [CrossRef] 